\section{(6) OPEN ACCESS}

\title{
Four hundred and sixty brands of e-cigarettes and counting: implications for product regulation
}

\author{
Shu-Hong Zhu, Jessica Y Sun, Erika Bonnevie, Sharon E Cummins, Anthony Gamst, \\ Lu Yin, Madeleine Lee
}

Moores Cancer Center, University of California San Diego, La Jolla, California, USA

\section{Correspondence to}

Dr Shu-Hong Zhu,

Department of Family and

Preventive Medicine, University

of California, San Diego, 9500

Gilman Drive, MC 0905,

La Jolla, CA 92093-0905,

USA; szhu@ucsd.edu

Received 11 March 2014

Revised 8 May 2014

Accepted 12 May 2014

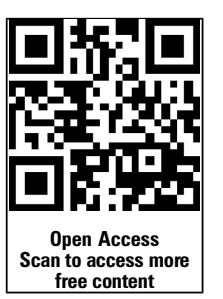

CrossMark

To cite: Zhu S-H, Sun JY, Bonnevie $\mathrm{E}$, et al. Tob Control 2014;23:iii3-iii9.

\begin{abstract}
Introduction E-cigarettes are largely unregulated and internet sales are substantial. This study examines how the online market for e-cigarettes has changed over time: in product design and in marketing messages appearing on websites.
\end{abstract}

Methods Comprehensive internet searches of Englishlanguage websites from May-August 2012 and December 2013-January 2014 identified brands, models, flavours, nicotine strengths, ingredients and product claims. Brands were divided into older and newer groups (by the two searches) for comparison.

Results By January 2014 there were 466 brands (each with its own website) and 7764 unique flavours. In the 17 months between the searches, there was a net increase of 10.5 brands and 242 new flavours per month. Older brands were more likely than newer brands to offer cigalikes $(86.9 \%$ vs $52.1 \%, p<0.01)$, and newer brands more likely to offer the more versatile eGos and mods $(75.3 \%$ vs $57.8 \%, p<0.01)$. Older brands were significantly more likely to claim that they were healthier and cheaper than cigarettes, were good substitutes where smoking was banned and were effective smoking cessation aids. Newer brands offered more flavours per brand (49 vs 32, $p<0.01)$ and were less likely to compare themselves with conventional cigarettes.

Conclusions The number of e-cigarette brands is large and has been increasing. Older brands tend to highlight their advantages over conventional cigarettes while newer brands emphasise consumer choice in multiple flavours and product versatility. These results can serve as a benchmark for future research on the impact of upcoming regulations on product design and advertising messages of e-cigarettes.

\section{INTRODUCTION}

Electronic cigarettes (e-cigarettes) are batterypowered nicotine delivery systems. They come in many varieties but can generally be grouped into three categories: cigalikes, which are models resembling conventional cigarettes in shape and size; eGos, which are larger than cigalikes, usually with a removable 'tank' that can be refilled with nicotine-containing e-liquid; and mods, which are usually larger than eGos and almost endlessly customisable. ${ }^{1}$

E-cigarettes have generated considerable interest among potential consumers. ${ }^{2-6}$ Even before they had been promoted through large-scale television advertising, more than two-thirds of US adults, smokers and non-smokers, had heard of e-cigarettes. ${ }^{7}$ The use of e-cigarettes is increasing among adults and youth. ${ }^{6-9}$ Anticipating the market opportunities, Lorillard, a large American tobacco company, acquired a major e-cigarette brand, blu eCigs, in April 2013. ${ }^{10}$ This acquisition also initiated national paid advertising campaigns to promote e-cigarettes. ${ }^{11} 12$ Other tobacco companies quickly followed. Altria purchased the brand Green Smoke in 2014 and RJ Reynolds plans to begin selling its own VUSE brand nationally. ${ }^{13}{ }^{14}$ NJOY, the most well-known brand not owned by a tobacco company, has also conducted major advertising campaigns to tout the relative advantage of ecigarettes over conventional cigarettes. ${ }^{15-17}$

E-cigarettes are mostly unregulated. Some countries have imposed restrictions on the sale of certain types of e-cigarettes, ${ }^{18}$ but the availability of e-cigarettes in all varieties on the internet has made enforcement difficult. As this paper was going through editorial revision, the US Food and Drug Administration (FDA) proposed to deem ecigarettes as a tobacco product. ${ }^{19}$ The proposed rules will ban selling e-cigarettes to minors. It will not, however, ban internet sales. At this point, the e-cigarette market shows every sign of growing. In the USA alone, it is projected to reach $\$ 2$ billion in 2014. ${ }^{20} 21$

A significant portion of e-cigarette business is conducted on the internet, although it is difficult to ascertain the exact volume. Several sources estimate that it is about $30-50 \%$ of total e-cigarettes sold. ${ }^{22} 23$ There are reasons for the active internet market: It is relatively easy to set up a new ecigarette company online, with small financial investment. No large advertising budget is required to achieve a web presence. In addition, most existing e-cigarette companies have their own websites and most of them also sell e-cigarettes over the internet. Thus, the internet reflects the majority of the e-cigarette market when it comes to issues such as the number of brands available for consumers.

This paper examines e-cigarette brands that are advertised and sold on the internet. It is an update of our report on an internet search of e-cigarette brands in 2012, which found more than 250 brands available at the time. ${ }^{24}$ This updated internet search, it should be noted, was finished 3 months before the US FDA issued its deeming proposal. ${ }^{19}$

The present study has two related aims. First, it provides a basic description of how e-cigarette brands have presented themselves: what is being offered to consumers and what claims are made about any presumed advantages over cigarettes. Second, it compares the brands that were sold on the internet in 2012 with those that became available since then (up to January 2014). It was expected that many new brands would appear on 
the internet. Given that e-cigarettes have been largely unregulated so far, it would be interesting to examine how new brands compete with older, more established brands. By studying the changes taking place in an unregulated marketplace, useful insights might be gained to inform future regulatory policies.

\section{METHODS}

\section{Search methods}

Two comprehensive searches of e-cigarette brands found on the internet were conducted: the first from May 2012 to August 2012, and the second from December 2013 to January 2014. We used three search engines: Google, Yahoo and Bing, and 13 keywords: 'e-cigarette,' 'e cigarette,' 'e-cig,' 'e cig, ' 'ecig,' 'ecigs,' 'electronic cigarette,' 'electronic cig,' 'electronic nicotine delivery system,' 'vape,' 'vaper' and 'vaping.' The first 30 pages of each search were reviewed to capture any possible e-cigarette brand websites.

Non-English websites, sites that did not sell products directly to consumers (wholesale sites, manufacturer sites, product review sites) and resale sites such as eBay and Amazon were excluded. Also excluded were websites that did not offer online sales, even if their products were available to view on their website (eg, MarkTen and VUSE), and sites that only sold devices used predominantly for marijuana or other substances. The first search was done by a project manager with three research assistants. The project manager created the database, trained research assistants and supervised the coding process. The second search was done by a project manager with 14 research assistants. During the second search, researchers also revisited the websites of all brands found during the first search. For the second search, a new codebook was created with detailed instructions on how to identify brands, products and models, product claims, nicotine strengths, flavours and ingredients. The project manager performed daily quality assurance checks to ensure consistency and was available at all times during data collection to resolve any discrepancies or questions. All data analysis in this study was based on results from the second search. The only data used from the first search were the brand names found in 2012 .

\section{Measures}

Brands

A website was coded as carrying a brand if it identified at least one e-cigarette-related product (such as a cigalike, cartridge, atomiser or e-liquid) as its own through a distinct name or logo. Sites that sold only e-liquid but no e-cigarette hardware were not considered to have a brand and were excluded. Websites that, in addition to selling their own brand also sold other brands, were counted as having one brand. Thus, one site, one brand.

\section{Types and models}

There are three basic types of e-cigarettes: cigalikes, eGos and mods. A website could offer different models within each type. For example, a website might offer the eGo and the eGo VV. They would be counted as two different models of eGo. If products only varied in colour or flavour of e-liquid, then they were not counted as separate models.

Some e-cigarette sites also sold e-hookah (an electronic version of the traditional hookah), and e-cigars or e-pipes (electronic versions with a similar shape to traditional cigars or pipes). They were recorded separately and were included as different models.
Flavours

Every flavour available from each site was recorded, and the individual names were the focus of the analysis. In addition, each flavour was coded into one of eight categories, including Tobacco, Menthol, Tobacco-Menthol, Fruit, Dessert/Candy, Alcohol/Drinks, Snacks/Meals and Others. When relevant, flavours were coded by first ingredient. Flavours that referenced tobacco brands were coded as tobacco. Flavours described as minty, icy or frosty were coded as menthol. Flavours like cinnamon, almonds, 'normal' and 'mystery' were coded as Other. Flavours offered on the same website with similar, but not identical, names were counted as separate flavours. Do-it-yourself flavour concentrates were excluded.

\section{Ingredients}

A website was coded on whether it listed ingredients and, if so, how many ingredients were listed. The presence of two types of propellant, propylene glycol and vegetable glycerine, as well as the presence of water and nicotine was noted.

\section{Nicotine strengths}

Companies reported nicotine strengths in three ways: in milligrams, percentages or using descriptors (eg, low, medium, high). There was little correspondence between descriptors and milligrams or percentage of nicotine across brands, which made standardisation infeasible. Instead, we simply counted the number of strengths. If a website reported strength information in more than one way, they were recorded as separate strengths unless the website explicitly stated that they were the same strength.

\section{Claims made about e-cigarettes}

Claims were coded into six categories: (1) E-cigarettes are less harmful than conventional cigarettes. This includes statements such as: they are healthier, contain no carcinogens, no tar or no secondhand smoke. (2) E-cigarettes are a substitute for places where one cannot smoke. (3) E-cigarettes are cheaper than cigarettes. (4) A direct claim of e-cigarettes as an effective quitting aid. (5) An indirect claim of e-cigarettes as an effective quitting aid. An example of an indirect claim would be customer testimonials. (6) An explicit disclaimer that e-cigarettes are not approved as smoking cessation devices.

\section{Analysis}

Brands were divided into two groups: older brands (which were active on the internet in 2012 and 2014) and newer brands (found only in 2014). Older brands were further divided into those that were well advertised and those that were not. No comprehensive study of the advertising expenditure of ecigarette brands has been published. We used Richardson and colleagues' study, which identified five brands that were the most advertised, all of which were in the older brand group identified in this search. ${ }^{25}$ The top-5 were: blu eCigs, NJOY, Green Smoke, Vapor4life and White Cloud. Logistic regression was used to assess differences in rates between old and new brands, while permutation t-tests were used to test for differences in counts of flavours and nicotine strengths. All calculations were done using R V.2.15.0. ${ }^{26}$

\section{RESULTS}

\section{Brands and models}

The initial search in 2012 identified 288 unique e-cigarette brands. In the follow-up search 17 months later, 37 of those 
Table 1 A comparison of products and models offered by the 466 e-cigarette brands, 2014

\begin{tabular}{|c|c|c|c|c|c|c|}
\hline & \multicolumn{4}{|c|}{ Older brands* $(\mathrm{N}=251)$} & \multirow{2}{*}{$\begin{array}{l}\text { Newer brandst }(\mathrm{N}=215) \\
\text { Newer brands } \\
(\mathrm{N}=215) \\
\%\end{array}$} & \multirow[b]{2}{*}{$\begin{array}{l}\text { Older vs newer } \\
\text { brands } \\
p \text { value }\end{array}$} \\
\hline & $\begin{array}{l}\text { Top-5 brands } \\
(\mathrm{N}=5) \\
\%\end{array}$ & $\begin{array}{l}\text { Other brands } \\
(\mathrm{N}=246) \\
\%\end{array}$ & $\begin{array}{l}\text { Top- } 5 \text { vs others } \\
\text { p value }\end{array}$ & $\begin{array}{l}\text { Older brands combined } \\
(N=251) \\
\%\end{array}$ & & \\
\hline Cigalike & 100.0 & 86.6 & $<0.01$ & 86.9 & 52.1 & $<0.01$ \\
\hline eGo & 20.0 & 58.5 & 0.13 & 57.8 & 75.3 & $<0.01$ \\
\hline Mod & 20.0 & 28.0 & 0.71 & 27.9 & 45.1 & $<0.01$ \\
\hline \# of models (mean) & 4.2 & 5.3 & 0.40 & 5.5 & 6.3 & 0.25 \\
\hline
\end{tabular}

brands were no longer active on the internet. The follow-up search identified 215 new brands. Thus, the net increase was about 10.5 brands per month. The total number of brands in January 2014 was $466(215+288-37=466)$.

Table 1 shows the types of products and number of models offered by these brands. Overall, older brands were significantly more likely to offer cigalikes than newer brands $(86.9 \%$ vs 52.1\%). Among all older brands, the top-5 group was even more likely to offer cigalikes $(100 \%$ vs $86.6 \%)$. In contrast to older brands, newer brands were more likely to offer eGos (75.3\% vs $57.8 \%)$ and mods $(45.1 \%$ vs $27.9 \%)$. The top-5 group was the least likely to offer either eGos or mods (20\%). Only one of the top-5 brands (Vapor4Life) sold eGos and mods. The rest sold only cigalikes.

The average number of models sold per website was 5.8 with no significant difference between older and newer brands (5.5 vs 6.3). The top-5 group had even fewer models, but it was not statistically significant.

EGos and mods allow for the hardware and e-liquid to be sold separately because they are customisable and contain refillable tanks. Table 2 shows whether brands carried their own branded hardware or e-liquid. Older brands were more likely to have their own brand of hardware than newer brands $(85.7 \%$ vs $64.7 \%$ ) while newer brands were more likely to have own brand of e-liquid than older brands $(65.6 \%$ vs $44.6 \%)$. The top-5 group always carried their own brand of hardware (100\%). Among the top-5, only Vapor4Life carried its own brand of e-liquid. Blu eCigs did not sell e-liquid, though it did carry a rechargeable model and several types of prepackaged nicotine cartridges.

\section{Flavours and nicotine strength}

Table 3 shows the average number of flavours per brand. Newer brands had a significantly higher mean number of flavours than older ones (49 vs 32 ). The median was more than twice as large for the newer brands, 33 vs 15 .
The total unique flavours (in the sense of unique linguistic labels for flavour) for all the brands were 7764. Of these, 4110 were offered only by newer brands and not by older ones. In other words, about 242 new flavours were added per month, on average.

Among older brands, there was no statistical difference in number of flavours offered by the top- 5 brands and the rest of the older brands. However, the average masks the difference. Among the top-5 brands, only Vapor4life offered a large number of flavours, 119. The rest offered very limited flavours, with NJOY offering only two basic flavours: tobacco and menthol.

Among all 466 brands, 93.4\% offered Tobacco and 92.1\% offered Menthol. Some brands (24.8\%) also offered a tobaccomenthol blend. The next most popular type of flavour was Fruit, offered by $84.2 \%$ of brands, followed by Dessert/candy, 79.9\%, Alcohol/drinks, 77.5\%, Snacks/meals, 25.7\%, and Others, $44.5 \%$ (data not shown in the table).

Table 3 also shows the number of nicotine strengths offered per brand. The mean was 4.4 , with no difference between older and newer brands. It is important to note that about $83 \%$ of the brands offered zero nicotine as one option.

\section{Ingredients}

Overall, 75.2\% of all brands listed ingredients. Table 4 shows that older brands were slightly more likely to list ingredients, but the difference was not statistically significant. All of the top- 5 brands listed ingredients.

Table 4 also shows the five most commonly listed ingredients: nicotine, propylene glycol, vegetable glycerine/glycerol, flavouring and water. Older brands were more likely to list nicotine than newer brands $(93.4 \%$ vs $81.7 \%)$ and less likely to list propylene glycol $(84.8 \%$ vs $92.8 \%)$ or vegetable glycerine $(59.9 \%$ vs $88.2 \%$ ) than newer brands. Flavouring is another major category listed by older and newer brands, and older brands were more likely to list water.

Table 2 Branded hardware or e-liquid offered by the 466 e-cigarette brands, 2014

\begin{tabular}{|c|c|c|c|c|c|c|}
\hline & \multicolumn{4}{|c|}{ Older brands* $(\mathrm{N}=251)$} & \multirow{2}{*}{$\begin{array}{l}\text { Newer brandst }(\mathrm{N}=215) \\
\text { Newer brands } \\
(N=215) \\
\%\end{array}$} & \multirow[b]{2}{*}{$\begin{array}{l}\text { Older vs newer } \\
\text { brands } \\
p \text { value }\end{array}$} \\
\hline & $\begin{array}{l}\text { Top-5 brands } \\
\text { (N=5) } \\
\%\end{array}$ & $\begin{array}{l}\text { Other brands } \\
(\mathrm{N}=246) \\
\%\end{array}$ & $\begin{array}{l}\text { Top- } 5 \text { vs others } \\
\text { p value }\end{array}$ & $\begin{array}{l}\text { Older brands combined } \\
(N=251) \\
\%\end{array}$ & & \\
\hline Branded hardware & 100.0 & 85.4 & $<0.01$ & 85.7 & 64.7 & $<0.01$ \\
\hline Branded e-liquid & 20.0 & 45.1 & 0.28 & 44.6 & 65.6 & $<0.01$ \\
\hline Branded both & 20.0 & 37.8 & 0.43 & 37.5 & 38.6 & 0.80 \\
\hline
\end{tabular}

*Active on the internet in 2012 and 2014.

†Active on the internet in 2014 but not 2012. 
Table 3 A comparison of flavours and nicotine strengths offered by the 466 e-cigarette brands, 2014

\begin{tabular}{|c|c|c|c|c|c|c|}
\hline & \multicolumn{4}{|c|}{ Older brands* $(\mathrm{N}=251)$} & \multirow{2}{*}{$\begin{array}{l}\text { Newer brandst }(\mathrm{N}=215) \\
\text { Newer brands } \\
(\mathrm{N}=215)\end{array}$} & \multirow{2}{*}{$\begin{array}{l}\text { Older vs newer } \\
\text { brands } \\
p \text { value }\end{array}$} \\
\hline & $\begin{array}{l}\text { Top-5 brands } \\
(\mathrm{N}=5)\end{array}$ & $\begin{array}{l}\text { Other brands } \\
(\mathrm{N}=246)\end{array}$ & $\begin{array}{l}\text { Top- } 5 \text { vs others } \\
p \text { value }\end{array}$ & $\begin{array}{l}\text { Older brands combined } \\
(N=251)\end{array}$ & & \\
\hline \multicolumn{7}{|l|}{ \# of flavours per brand } \\
\hline Mean & 30 & 32 & 0.93 & 32 & 49 & $<0.01$ \\
\hline Median & 8 & 15.5 & & 15 & 33 & \\
\hline \multicolumn{7}{|l|}{ \# of nicotine strengths } \\
\hline Mean & 5.4 & 4.4 & 0.13 & 4.5 & 4.4 & 0.65 \\
\hline Median & 5 & 4 & & 4 & 5 & \\
\hline Zero nicotine offered & $80.0 \%$ & $84.1 \%$ & 0.85 & $84.1 \%$ & $81.9 \%$ & 0.55 \\
\hline
\end{tabular}

\section{Claims made about e-cigarettes}

Table 5 shows the claims that brands made in reference to conventional cigarettes. Older brands were significantly more likely to claim that their products were healthier than conventional cigarettes than were newer brands $(80.1 \%$ vs $59.1 \%)$. The top-5 brands were most likely to make that claim (100\%). Older brands were also significantly more likely to mention that ecigarettes could be used where conventional cigarettes are not allowed (76.5\% vs $46.5 \%)$. Again, $100 \%$ of top-5 brands made that claim on their websites. Older brands were also more likely to claim that their products were cheaper than conventional cigarettes $(70.1 \%$ vs $47.0 \%)$. Once again, all top-5 brands made that claim. Finally, older brands were more likely than newer brands to indirectly claim that their products are effective for smoking cessation (principally through testimonials), $60.6 \%$ vs $48.4 \%$, with no difference between the top-5 brands and the other older brands. Moreover, $11.6 \%$ of newer brands and $10 \%$ of older brands made a direct claim about the efficacy of ecigarettes to help smokers quit cigarettes, which was not statistically different. In contrast, none of the top-5 brands made such a direct claim. Older brands were significantly more likely to make a specific disclaimer about e-cigarettes' efficacy as a cessation aid (64.9\% vs $43.7 \%)$.

\section{DISCUSSION}

The number of e-cigarette brands sold on the internet is large and the variety of flavours staggering: more than 460 brands and 7700 flavours. Many of these brands were new in the sense that they were not found in our first comprehensive internet search in $2012 .{ }^{24}$ During the 17 months between the two searches (from August 2012 to January 2014), the number of brands increased by 10.5 per month and 242 new flavours were added to the menu of choices.

The present study focused on internet websites because analysis of the changing content of these websites could offer insights into the dynamics of the unregulated e-cigarette market. E-cigarettes were originally invented to mimic conventional cigarette smoking as closely as possible. ${ }^{27-29}$ They are still mostly called e-cigarettes by users because of a certain similarity to cigarettes. Over time, however, the product design has evolved and the advertising messages have changed.

In terms of product design, this study found that older brands were more likely than newer brands to anchor themselves to conventional cigarettes. They were more likely to offer cigalike products, whose design might provide users with a sense of continued cigarette smoking. ${ }^{27} 3031$ In contrast, newer websites were more likely to offer eGos and mods, which allow users to manipulate nicotine content or add other ingredients, a degree of customisation not associated with conventional cigarettes.

This shift towards eGos and mods was associated with an explosion of flavours. Websites often sold nicotine liquid (often called e-juice) separately from hardware, making it easy to add a variety of flavourings to the e-juice. Many brands sold similar hardware, perhaps from the same manufacturer, but created their own e-juices and then branded the whole package as if it were entirely new. In this fashion, new brands could come into the market with small hardware modifications, but a focus on creative labelling for new flavours.

Table 4 The likelihood of listing e-liquid ingredients and the five most commonly listed ingredients, 2014

\begin{tabular}{|c|c|c|c|c|c|c|}
\hline & \multicolumn{4}{|c|}{ Older brands* $(\mathrm{N}=251)$} & \multirow{2}{*}{$\begin{array}{l}\text { Newer brandst }(\mathrm{N}=215) \\
\text { Newer brands } \\
(\mathrm{N}=215) \%\end{array}$} & \multirow{2}{*}{$\begin{array}{l}\text { Older vs newer } \\
\text { brands } \\
p \text { value }\end{array}$} \\
\hline & $\begin{array}{l}\text { Top-5 brands } \\
(\mathrm{N}=5) \%\end{array}$ & $\begin{array}{l}\text { Other brands } \\
(\mathrm{N}=246) \%\end{array}$ & $\begin{array}{l}\text { Top- } 5 \text { vs others } \\
\text { p value }\end{array}$ & $\begin{array}{l}\text { Older brands combined } \\
(N=251) \%\end{array}$ & & \\
\hline$\%$ listing ingredients & 100.0 & 78.0 & $<0.01$ & 78.5 & 71.2 & 0.07 \\
\hline $\begin{array}{l}\text { Mean number of ingredients listed } \\
\text { Type of ingredients }\end{array}$ & 5.2 & 4.62 & 0.52 & 4.6 & 4.0 & $<0.05$ \\
\hline Nicotine & 100.0 & 93.2 & $<0.01$ & 93.4 & 81.7 & $<0.05$ \\
\hline Propylene glycol & 80.0 & 84.9 & 0.82 & 84.8 & 92.8 & 0.06 \\
\hline Vegetable glycerine/glycerol & 80.0 & 59.4 & 0.36 & 59.9 & 88.2 & $<0.01$ \\
\hline Flavouring & 100.0 & 70.3 & $<0.01$ & 71.1 & 65.4 & 0.45 \\
\hline Water & 20.0 & 47.9 & 0.24 & 47.2 & 33.3 & $<0.01$ \\
\hline
\end{tabular}

*Active on the internet in 2012 and 2014.

†Active on the internet in 2014 but not 2012. 
Table 5 Claims made about e-cigarettes, 2014

\begin{tabular}{|c|c|c|c|c|c|c|}
\hline & \multicolumn{4}{|c|}{ Older brands* $(\mathrm{N}=251)$} & \multirow{2}{*}{$\begin{array}{l}\text { Newer brandst }(\mathrm{N}=215) \\
\text { Newer Brands } \\
(\mathrm{N}=215) \%\end{array}$} & \multirow{2}{*}{$\begin{array}{l}\text { Older vs newer } \\
\text { brands } \\
p \text { value }\end{array}$} \\
\hline & $\begin{array}{l}\text { Top-5 brands } \\
(\mathrm{N}=5) \%\end{array}$ & $\begin{array}{l}\text { Other brands } \\
(\mathrm{N}=246) \%\end{array}$ & $\begin{array}{l}\text { Top- } 5 \text { vs others } \\
\text { p value }\end{array}$ & $\begin{array}{l}\text { Older brands combined } \\
(N=251) \%\end{array}$ & & \\
\hline Healthier than cigarettes & 100.0 & 79.7 & $<0.01$ & 80.1 & 59.1 & $<0.01$ \\
\hline Could be used where smoking is banned & 100.0 & 76.0 & $<0.01$ & 76.5 & 46.5 & $<0.01$ \\
\hline Cheaper than cigarettes & 100.0 & 69.5 & $<0.01$ & 70.1 & 47.0 & $<0.01$ \\
\hline Effective quitting aid (indirect claim) & 60.0 & 60.6 & 0.98 & 60.6 & 48.4 & $<0.05$ \\
\hline Effective quitting aid (direct claim) & 0.0 & 10.2 & $<0.01$ & 10.0 & 11.6 & 0.57 \\
\hline Disclaimer & 80.0 & 64.6 & 0.49 & 64.9 & 43.7 & $<0.01$ \\
\hline
\end{tabular}

*Active on the internet in 2012 and 2014.

tActive on the internet in 2014 but not 2012.

This change in hardware and flavours suggests that newer brands shifted their emphasis towards consumer choice rather than focusing on advantages over conventional cigarettes. Instead of comparing themselves with cigarettes, newer brands appeared to style themselves as new nicotine delivery systems. The number of flavours available through these e-cigarette brands is so large that it is hard to compare with conventional cigarettes currently sold in the US market, which are allowed only two flavours, tobacco and menthol. ${ }^{32} 33$

Along with the changing product design, the messages these brands used to promote themselves on the internet have also changed. Newer brands were significantly less likely to make those claims that made e-cigarettes controversial in the first place. $^{28} 34 \quad 35$ They were less likely to claim that e-cigarettes were less harmful than conventional cigarettes. They were less likely to address the question of e-cigarettes' efficacy as a smoking cessation aid. While direct claims about cessation efficacy may be prohibited by law, it is easy to make indirect claims about cessation through testimonials. However, newer brands were significantly less likely to do so. They were also less likely to mention that e-cigarettes could be useful substitutes in places where cigarette smoking is not allowed. Finally, they were less likely to compare their price with that of conventional cigarettes. In short, newer brands seem to be moving away from using cigarettes as the reference.

This contrast in product design and advertising message is most salient when comparing the top- 5 older brands with newer brands. These five brands clearly anchored themselves to conventional cigarettes. They all offered cigalike products (compared with only 52\% of newer brands) and limited their flavours, with NJOY offering only tobacco and menthol. The top-5 brands were much more likely to claim the relative advantage of using e-cigarettes. All claimed their e-cigarettes were less harmful than cigarettes. All of them mentioned that they could be consumed in places where smoking is not allowed, and 80\% mentioned that they were cheaper than cigarettes.

What are the regulatory implications of this analysis? To begin with, the following discussion assumes that e-cigarettes will continue to be legally available in one form or another. It also assumes that cigarettes, the most deadly tobacco product available, will continue to be legal for the foreseeable future.

Given that cigarettes are available, an important frame of reference in regulating e-cigarettes is how the use of e-cigarettes impacts the smoking prevalence of a given population. Even though the risk of long-term e-cigarette use is unknown, most tobacco control researchers would agree that these risks are likely much smaller than those associated with continued cigarette smoking at the individual level. However, people disagree sharply when it comes to the impact of e-cigarette use on smoking prevalence at the population level. There are arguments on both sides ${ }^{27} 30{ }^{36}$ : one side is concerned that the increasing use of e-cigarettes will promote cigarette smoking. The other argues that e-cigarettes will help current smokers quit smoking, increasing the population cessation rate.

Given that there is no hard evidence for the impact of ecigarettes on smoking prevalence in either direction at this point, it seems prudent that regulations on e-cigarettes be carried out in two phases.

The first phase of regulation would focus on minimising the risks associated with the e-cigarette products themselves. E-cigarette companies should be required to properly list ingredients and nicotine strengths, and follow good manufacturing practices to ensure the safety of their products and avoid adulteration and misbranding. ${ }^{37}$ Containers for e-liquid should be required to be child-proof, ensuring that children are unable to swallow large doses of nicotine-containing liquids. No claim regarding efficacy for quitting or any other outcome should be allowed without evidence. Sale to minors should be banned. The clean indoor air policy restricting cigarette smoking should be applied to e-cigarettes as well. These basic policies will help protect consumers from substandard products and reduce the chance of children being put at risk. ${ }^{38} 3940$ Most of these have been included in European regulations on e-cigarettes and the recently issued deeming proposal by the US FDA. ${ }^{19} 41$ The present study found that many brands have chosen to list their ingredients, but it is not clear how accurate the lists are. The rules the FDA has just proposed, once put into effect, will help reduce product impurities and standardise information on nicotine content so that e-cigarette users can be more informed about the products they are using.

Restrictions on the use of e-cigarettes indoors does not fall under the purview of FDA regulation, but local or state level ordinances have already been passed in many places. One rationale for these policies is to help protect the anti-smoking social norms. ${ }^{36}$ As shown in table 5 , many e-cigarette websites advertise their products as a way of getting around existing secondhand smoke policies, a message that could have a detrimental effect on the current tobacco control norm.

The second phase of regulation requires more data. Several important research questions arose from the present study. The study shows that as the product design shifted from cigalikes towards eGos/mods, the advertising messages associated with these products also changed. Does this shift in advertising messages anticipate changing user characteristics? Will there be a 
differential effect of these two types of products either on smoking cessation or on smoking uptake?

More specifically, which product, cigalike or eGo/mod, will be more likely used by smokers to switch completely from conventional cigarettes to e-cigarettes? And which is more likely to be associated with prolonged dual use? Furthermore, which product appeals more to non-smoking youth and which is associated with a greater transitional probability to conventional cigarettes? Is it possible that the newer products, which continue to move away from being cigarette-like, will actually render conventional cigarettes unattractive to youth? Or will the great availability of flavours in the new products lead to a dramatic increase of e-cigarette users such that even a small probability of transition from these users will lead to a large number of new smokers? These are critical questions that future research needs to address to help formulate policies in the next phase of regulation.

A two-phase regulation approach might seem slow, but it is prudent given our current lack of knowledge. For example, regulation could severely restrict flavours based on the assumption that flavoured products will appeal to youth ${ }^{42} 43$ and that the use of e-cigarettes will lead more youth to smoke cigarettes. However, such regulation may primarily benefit the established brands, such as the top-5 in this study, which offer mainly cigalike products (in design and in flavour), rather than actually reducing smoking prevalence. It is conceivable that youth may turn to cigalike products if the more flavoured eGo types are not available. If the transition probability to smoking from these cigalike products is actually higher, then the restriction in flavouring will actually lead to more smokers in the long run. In other words, the existing vibrant e-cigarette market described in this study suggests that regulation based on insufficient scientific data might run the risk of only changing the market share of different e-cigarette brands rather than smoking prevalence itself. The implementation of the currently proposed FDA rules may or may not significantly reduce the number of brands that are owned by small companies. But stricter requirements, such as those similar to the FDA drug approval process, would certainly favour brands with strong financial backing. Most of those brands would be owned by tobacco companies. Obviously, tobacco companies will be more concerned with protecting their cigarette market share than companies that do not produce cigarettes. Regulatory policy making should be concerned with unintended consequences. A key objective of e-cigarette regulation should still be to strive for a net positive effect on smoking prevalence.

\section{What this paper adds}

- This paper presents the first comprehensive study of e-cigarette brands sold on the internet and found that the number of e-cigarette brands and the variety of flavours they offer are very large (more than 460 brands and 7700 flavours).

- Older brands of e-cigarettes were more likely to highlight their advantages over conventional cigarettes, whereas newer brands were more likely to emphasise consumer choice in models and in flavours.

- The dynamics of the current e-cigarette market present significant challenges to regulatory policy making.
Acknowledgements The authors thank Lesley Copeland, Yifei Huang, Mingyu Yang and the many research assistants who helped in data collection, and also Christopher Anderson, Caroline Chen and three anonymous reviewers for their helpful comments on the earlier draft of the paper.

Contributors Study conceptualisation: S-HZ; Data collection: JYS, ML, SEC, EB; Data analysis and interpretation: $\mathrm{S}-\mathrm{HZ}, \mathrm{AG}, \mathrm{LY}, \mathrm{JYS}, \mathrm{SEC}$; Writing: $\mathrm{S}-\mathrm{HZ}, \mathrm{EB}, \mathrm{SEC}, \mathrm{AG}, \mathrm{JYS}$.

Funding This study was supported by the National Cancer Institute of the National Institutes of Health under the State and Community Tobacco Control Initiative, Award Number U01CA154280. The content is solely the responsibility of the authors and does not necessarily represent the official views of the National Institutes of Health.

\section{Competing interests None.}

Provenance and peer review Not commissioned; externally peer reviewed.

Open Access This is an Open Access article distributed in accordance with the Creative Commons Attribution Non Commercial (CC BY-NC 3.0) license, which permits others to distribute, remix, adapt, build upon this work non-commercially, and license their derivative works on different terms, provided the original work is properly cited and the use is non-commercial. See: http://creativecommons.org/ licenses/by-nc/3.0/

\section{REFERENCES}

1 Farsalinos KE, Romagna G, Tsiapras D, et al. Characteristics, perceived side effects and benefits of electronic cigarette use: a worldwide survey of more than 19,000 consumers. Int J Environ Res Public Health 2014;11:4356-73.

2 Choi K, Forster JL. Beliefs and experimentation with electronic cigarettes: a prospective analysis among young adults. Am J Prev Med 2014;46:175-8

3 Etter JF, Bullen C. Electronic cigarette: users profile, utilization, satisfaction and perceived efficacy. Addiction 2011;106:2017-28.

4 Kralikova E, Novak J, West 0 , et al. Do e-cigarettes have the potential to compete with conventional cigarettes?: a survey of conventional cigarette smokers' experiences with e-cigarettes. Chest J 2013;144:1609-14.

5 Pepper JK, Reiter PL, McRee A, et al. Adolescent males' awareness of and willingness to try electronic cigarettes. J Adolesc Health 2013;52:144-50.

6 Regan AK, Promoff G, Dube SR, et al. Electronic nicotine delivery systems: adult use and awareness of the 'e-cigarette' in the USA. Tob Control 2013;22:19-23.

7 Zhu S, Gamst A, Lee $M$, et al. The use and perception of electronic cigarettes and snus among the U.S. population. PLOS ONE 2013;8:e79332.

8 Centers for Disease Control and Prevention (CDC). Notes from the field: Electronic cigarette use among middle and high school students-United States, 2011-2012. MMWR Morb Mortal Wkly Rep 2013;62:729-30.

9 Pearson JL, Richardson A, Niaura RS, et al. E-cigarette awareness, use, and harm perceptions in US adults. Am J Public Health 2012;102:1758-66.

10 Stock K. E-cig startups band together as big tobacco looms-Businessweek. BusinessWeek: Companies \& Industries February 2013. http://www.businessweek. com/articles/2014-02-13/e-cig-startups-band-together-as-big-tobacco-looms (accessed 4 Mar 2014)

11 Elliott S. Campaigns for electronic cigarettes borrow from their tobacco counterparts. New York Times 6 December 2012. http://www.nytimes.com/2012/12/06/business/ media/campaigns-for-electronic-cigarettes-borrow-from-their-tobacco-counterparts.html (accessed 11 Mar 2014).

12 Richardson A, Ganz O, Stalgaitis C, et al. Noncombustible tobacco product advertising: how companies are selling the new face of tobacco. Nicotine Tob Res 2014;16:606-14.

13 Fitch Ratings. Altria Green Smoke buy highlights industry e-cig interest. Fitch Ratings 5 February 2014. https://www.fitchratings.com/creditdesk/press_releases/ detail.cfm?pr id=819650 (accessed 11 March 2014).

14 Craver R. Reynolds to market Vuse at SXSW. Winston-Salem Journal 3 March 2014 http://www.journalnow.com/business/business_news/reynolds-to-market-vuse-at-sxsw/ article_49aee7e8-a313-11e3-b7d0-0017a43b2370.html (accessed $11 \mathrm{Mar} 2014$ ).

15 Sebastian M. NJoy E-cig TV spot insists 'friends don't let friends smoke'. Advert Age 2 January 2014. http://adage.com/article/media/njoy-e-cig-tv-spot-insists-friendsfriends-smoke/290886/ (accessed 11 Mar 2014).

16 Wallace B. Smoke without fire. New York Magazine 28 April 2013. http://nymag. com/news/features/e-cigarettes-2013-5 (accessed 11 Mar 2014)

17 Stevenson A. NJOY, E-cigarette maker, receives funding valuing it at \$1 billion. New York Times 28 February 2014. http://dealbook.nytimes.com/2014/02/28/ njoy-e-cigarette-maker-receives-funding-valuing-it-at-1-billion/ (accessed 11 Mar 2014)

18 Wikipedia. Electronic cigarette. Wikipedia, 2014. http://en.wikipedia.org/wiki/ Electronic cigarette (accessed 11 Mar 2014)

19 Food and Drug Administration. Deeming tobacco products to be subject to the federal Food, Drug, and Cosmetic Act, as amended by the Family Smoking Prevention and Tobacco Control Act; Regulations on the Sale and Distribution of Tobacco Products and Required Warning Statements for Tobacco Products. Fed Regist 2014. http://federalregister.gov/a/2014-09491. 
20 Herzog B, Gerberi J. E-cigs revolutionizing the tobacco industry. Wells Fargo Securities 2013. http://www.smallcapfinancialwire.com/wp-content/uploads/2013/11/E-CigsRevolutionizing-the-Tobacco-Industry-Interactive-Model.pdf (accessed 11 Mar 2014).

21 Euromonitor International. E-cigarettes: A US\$2 billion global industry-who should be worried? Euromonitor International 23 November 2012. http://blog.euromonitor. com/2012/11/e-cigarettes-a-us2-billion-global-industry-who-should-be-worried.html (accessed 11 Mar 2014).

22 Noel JK, Rees VW, Connolly GN. Electronic cigarettes: A new 'tobacco' industry? Tob Control 2011:20:81-81.

23 The Smoke Free Alternatives Trade Association. FDA corrects misleading Wall Street Journal report regarding the ban on electronic cigarette online sales. Smokefree Alternatives Trade Association 27 August 2013. http://www.sfata.org/fda-correctsmisleading-wall-street-journal-report-regarding-the-ban-on-electronic-cigarettesonline-sales/ (accessed 11 Mar 2014).

24 Lee $\mathrm{M}$, Zhu S, Huang $\mathrm{Y}$, et al. A survey of more than $250 \mathrm{E}$-cigarette brands on the internet. Poster POS3-73. Presented at the Society for Research on Nicotine and Tobacco (SRNT) 19th Annual Meeting; Boston, MA, 13-16 March 2013.

25 Richardson A, Ganz O, Vallone D. Tobacco on the web: Surveillance and characterisation of online tobacco and e-cigarette advertising. Tob Control. Published Online First: 14 February 2014. doi:10.1136/tobaccocontrol-2013-051246

26 The R Project for Statistical Computing. An introduction to R. The R Project for Statistical Computing, 6 March 2014. http://cran.r-project.org/doc/manuals/R-intro. html (accessed 11 Mar 2014).

27 Cahn Z, Siegel M. Electronic cigarettes as a harm reduction strategy for tobacco control: A step forward or a repeat of past mistakes? J Public Health Policy 2011:32:16-31.

28 Bell K, Keane H. Nicotine control: E-cigarettes, smoking and addiction. Int I Drug Policy 2012;23:242-7.

29 Etter J, Bullen C. Electronic cigarette: Users profile, utilization, satisfaction and perceived efficacy. Addiction 2011;106:2017-28.

30 Polosa R, Rodu B, Caponnetto P, et al. A fresh look at tobacco harm reduction: the case for the electronic cigarette. Harm Reduct J 2013;10:19.

31 Caponnetto P, Campagna D, Papale G, et al. The emerging phenomenon of electronic cigarettes. Expert Rev Respir Med 2012;6:63-74.
32 United States Congress. Family smoking prevention and tobacco control act. 2009; H.R. 1256(111):H.R. 1256.

33 Mitka M. FDA exercises new authority to regulate tobacco products, but some limits remain. JAMA 2009;302:2078-81.

34 Paek H, Kim S, Hove T, et al. Reduced harm or another gateway to smoking? source, message, and information characteristics of e-cigarette videos on YouTube. J Health Commun 2014;19(5):545-60.

35 Benowitz NL, Goniewicz ML. The regulatory challenge of electronic cigarettes. JAMA 2013;310:685-6.

36 Fairchild AL, Bayer R, Colgrove J. The Renormalization of Smoking? E-Cigarettes and the Tobacco "Endgame". N Engl J Med 2014;370:293-5.

37 US Food and Drug Administration. Regulation of E-cigarettes and other tobacco products. US Food and Drug Administration, 2011. http://www.fda.gov/newsevents/ publichealthfocus/ucm 252360.htm (accessed 11 Mar 2014).

38 CBS News Staff. Electronic cigarette explodes in man's mouth, causes serious injuries. CBS NEWS 16 February 2012. http://www.cbsnews.com/news/ electronic-cigarette-explodes-in-mans-mouth-causes-serious-injuries/ (accessed 11 Marc 2014)

39 Williams M, Villarreal A, Bozhilov K, et al. Metal and silicate particles including nanoparticles are present in electronic cigarette cartomizer fluid and aerosol. PLOS ONE 2013;8:e57987.

40 Durmowicz EL. The impact of electronic cigarettes on the paediatric population. Tob Control 2014;23(Suppl 2):ii41-6.

41 European Parliament, Council of the European Union. Directive 2014/40/EU of the European Parliament and of the Council. Official Journal of the European Union L 127, 29 April 2014. http://ec.europa.eu/health/tobacco/docs/dir_201440_en.pdf (accessed 6 May 2014).

42 Carpenter CM, Wayne GF, Pauly JL, et al. New cigarette brands with flavors that appeal to youth: Tobacco marketing strategies. Health Aff (Millwood) 2005:24:1601-10.

43 Choi K, Fabian L, Mottey N, et al. Young adults' favorable perceptions of snus, dissolvable tobacco products, and electronic cigarettes: Findings from a focus group study. Am J Public Health 2012;102:2088-93. 